\title{
Breast Cancer Awareness among Women in an Urban Setup in Western India
}

\begin{abstract}
Introduction: Breast cancer is a leading cause of death among women globally. Better outcomes for patients can be ensured by early detection and treatment. Early detection requires a high degree of awareness about the various aspects of cancer including etiology, risk factors, signs and symptoms, and breast self-examination (BSE) practices. The purpose of this study was to assess the knowledge and awareness related to breast cancer along with willingness for treatment, among women in an urban setup in Western India. Materials and Methods: We conducted a cross-sectional study with 500 women belonging to the age group of 18-70 years residing in an urban area of Mumbai. Data were obtained through the use of a structured questionnaire over a period of 6 months (AprilSeptember 2016). Results: Over half of the respondents (71.42\%) knew the symptoms of breast cancer. Awareness regarding the risk factors was varied. Although most (85.71\%) of the respondents knew about BSE, contrastingly very few (38.09\%) actually performed it. Awareness regarding diagnostic tests was limited to mammography and biopsy, but $90.47 \%$ of the women were willing to undergo these tests. $66.67 \%$ of women reported that the best treatment for breast cancer was surgery. Conclusion: Awareness of the different presentations of breast cancers (other than lump) is limited and so is the knowledge pertaining to risk factors. A lower level of education is most likely responsible for the low level of awareness and this is the main obstacle for undergoing regular cancer screening and early detection. There is a need of developing an effective health education programs to educate women about breast cancer, propagate valid information via the media, and promote early detection of breast cancer to ensure better outcomes.
\end{abstract}

Keywords: Awareness, breast cancer, India, risk factors, urban setup

\section{Introduction}

Breast cancer is a major health problem and is the second leading cause of cancer deaths in women. ${ }^{[1]}$ More than two-third of the patients are already in an advanced and incurable stage at the time of diagnosis. ${ }^{[2]}$ The World Health Organization described early detection of breast cancer as "the cornerstone of breast cancer control ${ }^{[3]}$ " and this can only be achieved via awareness in the masses. Millions of cancer-related deaths could be averted every year if patients have timely access to early detection via regular screening and treatment. ${ }^{[4]}$ In a study conducted in India, it was found that according to oncologists, late presentation of breast cancer was the most important cause of decreased survival among women..$^{[5]}$

Lack of knowledge about breast cancer prevents women from accessing screening facilities, performing breast

This is an open access article distributed under the terms of the Creative Commons Attribution-NonCommercial-ShareAlike 3.0 License, which allows others to remix, tweak, and build upon the work non-commercially, as long as the author is credited and the new creations are licensed under the identical terms.

For reprints contact: reprints@medknow.com self-examinations (BSEs), thus delaying diagnosis and treatment which inadvertently lead to high morbidity and mortality rates. ${ }^{[6]}$

The purpose of the study was to assess the knowledge and attitudes related to breast cancer in women from an urban setup including etiology, risk factors, symptoms, BSE practices, different modalities of diagnosis, and treatment options which are available.

\section{Materials and Methods}

This study included all women in the age group of 18-70 years residing in an urban setup in Mumbai. Women below 18 and above 70 years of age and those not willing to participate in the study were excluded.

\section{Study design}

A cross-sectional study was conducted by selecting a house randomly for identifying the participants. Data were collected in sequence until estimated sample size was

How to cite this article: Singh R, Shetty N, Rai P,
Yadav G, Gandhi M, Naveed M, et al. Breast cancer
awareness among women in an urban setup
in Western India. Indian J Med Paediatr Oncol
2018;39:215-8.

Ranvijay Singh, Nishitha Shetty', Parashar Rai', Ghanshyam Yadav², Mukti Gandhi', Maryam Naveed ${ }^{4}$, Ashwini M. Ronghe ${ }^{5}$

Department of Medicine, RCSM Government Medical College, Kolhapur, ${ }^{2}$ Department of Medicine, Topiwala National Medical College and BYL Nair Hospital, '5epartment of Medicine, Grant Medical College, Mumbai, Maharashtra, ${ }^{1}$ Department of Medical Oncology, Father Muller Medical College, Mangalore, Karnataka, ${ }^{3}$ Department of Medicine, NHL Municipal Medical College, Ahmedabad, Gujarat, India, ${ }^{4}$ Department of Medicine, CMH Lahore Medical College, Lahore, Pakistan

Address for correspondence: Dr. Ranvijay Singh, Department of Medicine, RCSM, Government Medical College, CPR Hospital, Near Dasara Chowk, Kolhapur - 416002 , Maharashtra, India.

E-mail: rvs2384@gmail.com

Access this article online

Website: www.ijmpo.org

DOI: 10.4103/ijmpo.ijmpo_165_17 Quick Response Code:

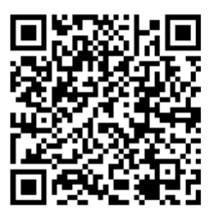


completed. A questionnaire was developed with the help of experts and review of literature. This questionnaire was modified after a pilot study and was then validated for data collection. A home-to-home visit was done. Study participants were explained about the aims and requirements of the study, and written informed consent was obtained before providing the questionnaire.

\section{Statistical analysis}

SPSS Version 20.0 (Armonk, NY: IBM Corp) was used for analysis. Chi-square test was used for the analysis of categorical variables and Student's $t$-test for continuous variables.

\section{Results}

More than half of the respondents (71.42\%) knew the symptoms of breast cancer [Table 1]. The most common symptom was breast lump $(90.47 \%)$ followed by pain in the breast $(28.09 \%)$, bleeding or discharge through nipple $(12.78 \%)$, changes over the skin of the breast $(5.32 \%)$, cyclical tenderness $(3.74 \%)$, and lump in the axilla $(1.56 \%)$. The source of this information was media in majority of women $(42.85 \%)$ while $34.56 \%$ obtained this information from patients with similar lesions and $28.57 \%$ from their doctor.

Awareness regarding risk factors for breast cancer is shown in Table 1. The fact that the propensity for breast cancer was genetically inherited was known to $80.95 \%$ of the respondents and $71.58 \%$ thought that breast implants increase the risk of breast cancer. If symptoms were experienced, most $(85.71 \%)$ women said that they would consult a doctor rather than wait and watch (14.28\%).

A majority (85.71\%) of women were aware of BSE and $90.47 \%$ thought it was important. A total of $38.09 \%$ of women performed BSE as advised by their doctor. The most common frequency of BSE was monthly (in 47.63\% women). A total of $61.91 \%$ of women did not perform BSE. Interestingly, $52.38 \%$ of women said that they would perform BSE if the result was beneficial and $23.80 \%$ said that they would do it the cure was known.

Women believed that breast cancer could be diagnosed by mammography $(80.95 \%)$, biopsy $(71.42 \%)$, computed tomography/magnetic resonance imaging (33.34\%), fine-needle aspiration cytology (4.76\%), and ultrasonography $(1.42 \%)$. A total of $90.47 \%$ of women were willing to undergo these tests.

When asked about treatment for breast cancer, 66.67\% of women thought that surgery was the best treatment followed by medicine (28.57\%) and Ayurveda (23.80\%). A total of $47.61 \%$ of women were willing to undergo surgical procedures for treatment.

When asked whether breast cancer was preventable, $80.95 \%$ of women agreed and thought that lifestyle

\begin{tabular}{|c|c|}
\hline \multicolumn{2}{|l|}{ Table 1: Results of the study } \\
\hline Variable & $\begin{array}{l}\text { Percentage } \\
\text { of women }\end{array}$ \\
\hline \multicolumn{2}{|l|}{ Awareness of symptoms } \\
\hline Lump in breast & 90.47 \\
\hline Pain in breast & 28.09 \\
\hline Bleeding/discharge through nipple & 12.78 \\
\hline Skin changes over the breast & 5.32 \\
\hline Cyclical breast tenderness & 3.74 \\
\hline Lump in axilla & 1.56 \\
\hline \multicolumn{2}{|l|}{ Awareness of general risk factors } \\
\hline Advancing age & 66.67 \\
\hline Early menopause & 33.34 \\
\hline Late menopause & 28.57 \\
\hline Oral contraceptive pills & 33.34 \\
\hline Obesity & 57.14 \\
\hline HRT & 47.61 \\
\hline \multicolumn{2}{|l|}{ Awareness about tests for diagnosis } \\
\hline Mammography & 80.95 \\
\hline Biopsy & 71.42 \\
\hline $\mathrm{CT} / \mathrm{MRI}$ & 33.34 \\
\hline FNAC & 4.76 \\
\hline USG & 1.42 \\
\hline \multicolumn{2}{|l|}{ Awareness about treatment of breast cancer } \\
\hline Surgery & 66.67 \\
\hline Medicine & 28.57 \\
\hline Ayurveda/other allied traditional fields & 23.80 \\
\hline \multicolumn{2}{|l|}{ Awareness about whom to consult } \\
\hline Gynecologist & 66.67 \\
\hline Family physician/primary care physician & 23.80 \\
\hline Surgeon & 19.04 \\
\hline \multicolumn{2}{|l|}{ Awareness about preventive factors } \\
\hline Lifestyle modification & 47.61 \\
\hline Good nutrition & 38.09 \\
\hline Avoiding tobacco and alcohol & 42.85 \\
\hline \multicolumn{2}{|l|}{ Source of information/awareness } \\
\hline All forms of media (TV, print, radio, internet etc.) & 42.85 \\
\hline Patient with similar lesion & 34.56 \\
\hline Physicians & 28.57 \\
\hline
\end{tabular}

CT - Computed tomography; MRI - Magnetic resonance imaging; FNAC - Fine-needle aspiration cytology; USG - Ultrasonography; HRT - Hormone replacement therapy

modifications such as physical activity (47.61\%), early diagnosis $(71.42 \%)$, good nutrition such as avoiding fat-rich food $(38.09 \%)$, and avoiding smoking and drinking alcohol $(42.85 \%)$ would prevent it. A total of $85.71 \%$ of women viewed breast cancer disease as curable.

\section{Discussion}

This study showed that most women know that breast lump (90.47\%) is a common symptom of breast cancer, but awareness regarding other symptoms was poor. A study conducted among Indian women in an urban area in 2008 showed that only $56 \%$ of women were aware of breast cancer, and among them, $51 \%$ knew at least one of the 
signs/symptoms, 53\% were aware that breast cancer can be detected early, and only $35 \%$ had knowledge about risk factors. ${ }^{[7]}$ Thus, awareness programs in India should also stress on other presentations of breast cancer and not just focus on lump in the breast. Most of them obtained this information from the media $(42.85 \%)$ and thus it is essential to ensure that correct information is being circulated. Women must be encouraged to talk to their physicians about information regarding breast cancers.

Awareness was better in educated women or working women as compared to homemakers. Similar associations have been found in other studies. Education is instrumental in changing the attitude toward breast cancer and it also improves compliance toward cancer screening. ${ }^{[8-10]}$ Another study which shows the importance of education was where individuals were divided into two groups as university graduates and high school lower graduates. It was found that higher educational levels were positively associated with BSE performance. ${ }^{[11]} \mathrm{BSE}$ is a simple yet effective technique of early detection of breast cancer. Awareness of BSE was high (85.71\%), but only 38.09\% of women performed BSE. When asked about the reason to not do it, the most common responses were "just never done it," "never thought about it," "my doctor didn't tell me," etc., Another study conducted among Indian teachers showed that only $36.1 \%$ of women had heard of the term BSE, only $13.4 \%$ knew about the recommended frequency of once a month, and only $7.3 \%$ knew about the appropriate position to perform it. ${ }^{[12]}$

Doctors, especially gynecologists, play a very important role in creating awareness of breast cancer and its risk factors as majority of the women said that they would approach a gynecologist (66.67\%) for symptoms experienced. Women were not against the practice of BSE as most of women said that they would perform BSE if the result was beneficial $(52.38 \%)$ which again proves that awareness is extremely essential to ensure compliance. Mammography and biopsy were the most common tests known to women and most were willing to undergo these tests. This was again attributed to the education level of the women. ${ }^{[8,9]}$ Another interesting finding was that awareness regarding these tests was high among married as compared to unmarried women. When asked about the treatment for breast cancer, $66.67 \%$ of women thought that surgery was the best treatment but only $47.61 \%$ were willing to undergo surgical procedures for treatment. This could be attributed to the fear of cosmetic issues and lack of awareness about breast conservation and reconstructive surgeries. ${ }^{[10-12]}$ Awareness of preventive measures such as lifestyle modification was appropriate. Another finding was $71 \%$ of women said that early diagnosis would help in diagnosis. ${ }^{[12]}$ Furthermore, many women said that breast cancer is curable provided it is detected early.

In India, the media publicity and policy efforts on cancer have primarily focused on tobacco use; however, there has hardly been any discussion of other important risk factors such as use of contraceptives, alcohol, breastfeeding history, and obesity. ${ }^{[13]}$ Efforts must be made to focus on these factors and there is an urgent need to explore these awareness deficits and stigma surrounding breast cancer. The limitation of this study was the cross-sectional nature of the study which did not allow for cause-effect relationship to be made, and after the study was conducted, there was no effort made to act to increase the level of knowledge among the women in whom this study was conducted.

\section{Conclusion}

Awareness is related to the education level of women and thus it is essential to develop an effective health education program which would cater to a vast variety of people coming from different educational, social, and cultural backgrounds. The results of this study can be extrapolated to acquire information regarding awareness of breast cancer in women in an urban setup. This in turn can be used to develop interventional programs with the help of health-care professionals, media, and the policymakers of the country.

\section{Acknowledgment}

We acknowledge the work of Medical Student (Joaquim Anthony Noguer, RCSM Government Medical College, Kolhapur, India, Email: joaquimnoguer@rediffmail.com) in data collection.

\section{Financial support and sponsorship}

Nil.

\section{Conflicts of interest}

There are no conflicts of interest.

\section{References}

1. Ferlay J, Soerjomataram I, Dikshit R, Eser S, Mathers C, Rebelo $\mathrm{M}$, et al. Cancer incidence and mortality worldwide: Sources, methods and major patterns in GLOBOCAN 2012. Int $\mathrm{J}$ Cancer 2015;136:E359-86.

2. Park K, Park K. Epidemiology of communicable diseases. Textbook of Preventive and Social Medicine. Banarsidas Bhanot: 2011;21:244-50.

3. WHO. Breast Cancer: Prevention and Control. Available from: http://www.who.int/cancer/detection/breastcancer/en/. [Last accessed on 2017 Aug 06].

4. World Health Organization. Cancer Control: Knowledge Into Action: WHO Guide for Effective Programmes. World Health Organization; 2007.

5. Bodapati SL, Babu GR. Oncologist perspectives on breast cancer screening in India- results from a qualitative study in Andhra Pradesh. Asian Pac J Cancer Prev 2013;14:5817-23.

6. Godfrey K, Agatha T, Nankumbi J. Breast cancer knowledge and breast self-examination practices among female university students in Kampala, Uganda: A Descriptive study. Oman Med J 2016;31:129-34.

7. Somdatta P, Baridalyne N. Awareness of breast cancer in women of an urban resettlement colony. Indian J Cancer 2008;45:149-53. 
8. Elango JK, Sundaram KR, Gangadharan P, Subhas P, Peter S, Pulayath $\mathrm{C}$, et al. Factors affecting oral cancer awareness in a high-risk population in India. Asian Pac J Cancer Prev 2009;10:627-30.

9. Pakfetrat A, Falaki F, Esmaily HO, Shabestari S. Oral cancer knowledge among patients referred to Mashhad dental school, Iran. Arch Iran Med 2010;13:543-8.

10. Modeste NN, Caleb-Drayton VL, Montgomery S. Barriers to early detection of breast cancer among women in a Caribbean population. Rev Panam Salud Publica 1999;5:152-6.
11. Gürdal SÖ, Saraçoğlu GV, Oran EŞ, Yankol Y, Soybir GR The effects of educational level on breast cancer awareness: A cross-sectional study in Turkey. Asian Pac J Cancer Prev 2012;13:295-300.

12. Khokhar A. Level of awareness regarding breast cancer and its screening amongst Indian teachers. Asian Pac J Cancer Prev 2009; 10:247-50.

13. Babu GR, Lakshmi SB, Thiyagarajan JA. Epidemiological correlates of breast cancer in South India. Asian Pac J Cancer Prev 2013;14:5077-83. 